\title{
Congelación Ultra Rápida de Espermatozoides Humanos: Efecto sobre la Función Espermática y Producción de Especies Reactiva de Oxígeno
}

\author{
Ultra Rapid Freezing in Human Spermatozoa: Effect on Sperm Function \\ and Reactive Oxygen Species Production
}

*Olga Berrios S. \& **** Raúl Sánchez G.

BERRIOS, S. O. \& SÁNCHEZ, G. R. Congelación ultra rápida de espermatozoides humanos: Efecto sobre la función espermática y producción de especies reactiva de oxígeno. Int. J. Morphol., 29(3):899-906, 2011.

RESUMEN: El incremento del número de pacientes que desean mantener su fertilidad, ya sea por motivos oncológicos o de fertilidad, como son los pacientes con enfermedades infecciosas virales trasmitidas por vía sexual, o que se someten en forma voluntaria a la esterilización quirúrgica, requieren de métodos de congelación que preserven en forma adecuada la función de los espermatozoides. En el área de la criobiología, la utilización de técnicas de congelación ultrarrápida ha permitido preservar en forma exitosa ovocitos, embriones y tejido ovárico. Este método se ha incorporado recientemente para preservar el gameto masculino. El presente estudio evalúa el efecto de la congelación ultrarrápida (vitrificación) sobre la función espermática de 10 donantes normozoospérmicos. Los espermatozoides se seleccionaron por Swim-up y la solución espermática se dividió en dos subfracciones. Una fracción se vitrificó sumergiéndola directamente en nitrógeno líquido mientras que la segunda se utilizó como control. En ambas fracciones se determinaron viabilidad, movilidad, potencial de membrana mitocondrial ( $\Psi M M i t)$, integridad del ADN, reacción de acrosoma espontánea e inducida, y superóxido intracelular $\left(\mathrm{O}_{2}\right.$ - $\left.^{-}\right)$. Se observó que la vitrificación preserva una adecuada función celular en un alto número de espermatozoides, siendo además un método simple, rápido y de menor costo, ya que no necesita equipo de congelación. No obstante, existe una significativa activación de la producción de especies reactivas de oxígeno, que conlleva a una prematura capacitación espermática, evento que es necesario de modular, especialmente si se utilizan estas células en técnicas de inseminación intrauterina. Futuros estudios con adición de antioxidantes a los medios de congelación parecen necesarios para optimizar esta técnica.

PALABRAS CLAVE: Espermatozoides humanos; Criopreservación; Congelación ultra rápida; Función espermática; Especies reactivas de oxígeno.

\section{INTRODUCCIÓN}

Constantemente se modifican los procedimientos de congelamiento a fin de obtener mejores resultados en los indicadores de funcionalidad espermática, para lograr de esta forma mayores porcentajes de embarazos (Stornelli et al., 2005). Las causas más frecuentes de pérdida de la función celular producidas por congelamiento, son alteraciones de la membrana plasmática, daño mitocondrial, deterioro en la integridad del ADN y aumento en la producción de las especies reactivas de oxígeno (ROS), todas con un efecto negativo sobre los indicadores esenciales para la fecundación (Desrosiers et al.; 2006; Ngmwuttiwong \& Kunathikom, 2007; Yildiz et al., 2007).

Recientemente, se ha descrito un método de criopreservación ultra rápida (vitrificación) que consiste en la exposición directa de la célula a nitrógeno líquido o a sus vapores, evitando así la cristalización del agua intracelular. Uno de los principios en que se basa este método es el enfriamiento ultrarápido de las células inmersas en una solución que lleva incorporado crioprotectores no permeables en alta concentración. La mezcla al ser enfriada no cristaliza, sino que se torna viscosa y pasa de líquido a un estado sólido (Fahy et al., 1984).

Los primeros ensayos de vitrificación realizados en espermatozoides no resultaron exitosos debido a la poca tolerancia de estos a las altas concentraciones de crioprotector (Isachenko et al., 2003). Posteriormente, se ha logrado vitrificar espermatozoides mediante aplicación directa de la solución espermática dentro de nitrógeno líquido (directly

* BIOREN-CEBIOR, Universidad de La Frontera, Temuco, Chile.

** Departamento de Ciencias Preclínicas, Facultad de Medicina, Universidad de La Frontera, Temuco, Chile. 
plunging), con crioprotectores no permeables utilizados en bajas concentraciones o sin la presencia de ellos (Isachenko et al., 2004a; 2004b; 2008). Este método ha hecho posible obtener porcentajes de viabilidad y movilidad aceptables, como también bajos porcentajes de fragmentación de ADN, lo que podría posibilitar el uso de estos espermatozoides en técnicas de reproducción asistida. No obstante, persiste un porcentaje cercano al $40 \%$ de células con daño a la membrana plasmática que posiblemente este asociado al incremento de las especies reactivas de oxigeno que se produce posterior a la descongelación. El objetivo de este trabajo es evaluar los efectos de la congelación ultra rápida sobre la función espermática y su potencial efecto en el incremento de radicales libres derivados del oxigeno.

\section{MATERIAL Y METODO}

Obtención de muestras. Se emplearon 10 muestras de líquido seminal obtenidas por masturbación de donantes normales, con abstinencia mínima de 2 días. Las muestras se mantuvieron a $37^{\circ} \mathrm{C}$ en estufa de cultivo durante $30-60$ minutos hasta su licuefacción. Posteriormente, se realizó un espermiograma y a aquellas muestras consideradas normales según la OMS (WHO, 2010) fueron utilizadas para el protocolo de evaluación de la función espermática.

Swim-up. Los espermatozoides fueron separados del líquido seminal por swim- up. Para ello, se procedió a lavar la muestra disponiendo alícuotas de $600 \mu \mathrm{l}$ de semen en tubos Falcon. A cada tubo con la muestra se añadieron $5 \mathrm{ml}$ de Human Tubal Fluid (HTF) (Quinn et al., 1985) y se centrifugaron a $400 \mathrm{~g}$ por $5 \mathrm{~min}$. Para la selección de los espermatozoides, se adicionó lentamente al pellet, HTF suplementado con HSA (Albúmina Sérica Humana) al 1\% y se incubó al menos 45 minutos a $37^{\circ} \mathrm{C}$. Finalmente, se procedió a retirar cuidadosamente el sobrenadante depositándolo en un tubo Falcon estéril.

Vitrificación y desvitrificación de las muestras. La suspensión espermática con los espermatozoides seleccionados fue dividida en dos fracciones, una de ellas fue sometida a vitrificación, mientras que la segunda permaneció sin vitrificar (control).

Vitrificación. Una fracción de los espermatozoides seleccionados por swim- up fue vitrificada, para lo cual, en un tubo Eppendorf se depositaron $600 \mu \mathrm{L}$ de HTF con $1 \%$ HSA conteniendo aproximadamente $8 \times 10^{6}$ espermatozoides $/ \mathrm{mL}$. Posteriormente se adicionaron $600 \mu \mathrm{L}$ sucrosa $0.5 \mathrm{M}$ en HTF y se dejó equilibrar la solución durante 5 min, con una concentración final de sucrosa $0.25 \mathrm{M}$. Se tomaron alícuotas de
$30 \mu \mathrm{L}$ de suspensión espermática y fueron agregadas directamente en nitrógeno líquido formándose esferas sólidas. Las esferas congeladas fueron depositadas en criotubos rotulados y almacenadas por al menos 24 horas a $-196^{\circ} \mathrm{C}$.

Desvitrificación. En tubos Falcon conteniendo $5 \mathrm{ml}$ de HTF-BSA $1 \%$ a $37^{\circ} \mathrm{C}$, se depositaron de a una las esferas de material congelado, agitando con vortex el tubo cada vez que una esfera era depositada dentro de éste. Se desvitrificaron no más de 5 esferas por tubo para evitar el enfriamiento del medio. Luego se equilibró la solución conteniendo los espermatozoides por 5 minutos a $37^{\circ} \mathrm{C}$ en estufa de cultivo y se centrifugó por $5 \mathrm{~min}$ a $1800 \mathrm{rpm}$. El pellet fue resuspendido en $0,2 \mathrm{ml}$ de HTF-BSA $1 \%$.

Evaluación de la funcionalidad espermática. En las fracciones vitrificadas y sin vitrificar se evaluó recuento espermático, viabilidad, movilidad, potencial de membra-

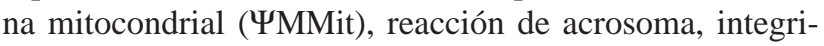
dad de ADN y determinación de superóxido $\left(\mathrm{O}_{22^{-}}\right)$

Viabilidad. En un portaobjetos se dispuso $10 \mu \mathrm{L}$ de la suspensión espermática. Sobre ésta se adicionaron $10 \mu \mathrm{L}$ de Eosina 5\%. Se cubrió con cubreobjeto de $18 \times 18 \mathrm{~mm}$ y se observó al microscopio óptico Zeiss. Se contaron al menos 200 espermatozoides y se consideraron vivos a los espermatozoides no teñidos por el colorante.

Movilidad. Se depositaron $10 \mu \mathrm{L}$ de suspensión espermática sobre un portaobjetos, se cubrió con un portaobjeto de $18 \times 18$ $\mathrm{mm}$ y se procedió a contar la movilidad progresiva.

Potencial de Membrana Mitocondrial. Se evaluó el YMMit utilizando el reactivo catiónico (55'66'-tetrachloro11'33'-tetraethyl-benzamidazolocarbocyanin iodide) presente en el kit KI-162 Reactivo JC-1 Mit-E- Y TM liofilizado (Kit Biomol). Brevemente, en un tubo Eppendorf se dispusieron $300 \mu \mathrm{L}$ de HTF con aproximadamente 1,2 millones de espermatozoides, se adicionó $1 \mu \mathrm{L}$ de reactivo JC-1, y se incubó en oscuridad a $37^{\circ} \mathrm{C}$ por 15 min. Posteriormente se centrifugó a $400 \mathrm{~g}$ por $10 \mathrm{~min}$, se retiró el sobrenadante y el pellet se resuspendió en $100 \mu \mathrm{L}$ de HTF. Se observaron 10 $\mu \mathrm{L}$ en microscopio de epifluorescencia (Zeiss, Axiolab). Se contabilizaron al menos 200 células.

Reacción de acrosoma. Para teñir los espermatozoides que presentaron reacción de acrosoma, se utilizó la lectina Pisum sativum, marcada con isotiocianato de fluoresceína (PSAFITC). Además se utilizó ioduro de propidio para diferenciar los espermatozoides muertos. Brevemente, a $300 \mu \mathrm{L}$ de suspensión espermática, conteniendo 2 millones de espermatozoides, se adicionan $15 \mu \mathrm{l}$ de PSA-FITC más 5 $\mu \mathrm{L}$ de ioduro de propidio. Se dejó incubando durante 15 
minutos a $37^{\circ} \mathrm{C}$ y se evaluaron 10.000 células en el citómetro de flujo FACSCalibur, Becton Dikinson.

Inducción de la reacción de acrosoma. La reacción de acrosoma se indujo con ionóforo de calcio. A $300 \mu \mathrm{L}$ de suspensión espermática conteniendo aproximadamente $2 \times 10^{6}$ espermatozoides $/ \mathrm{ml}$, se adicionaron $5 \mu \mathrm{L}$ de ionóforo de calcio $10 \mathrm{mM}$. La suspensión se incubó durante $15 \mathrm{~min}$ a $37^{\circ} \mathrm{C}$ y se procedió a la tinción PSA-FITC. Se evaluaron 10.000 células en el citómetro de flujo FACSCalibur, Becton Dikinson.

Integridad del ADN. La integridad del ADN se evaluó utilizando el test de TUNEL. Esta técnica se basa en la incorporación de nucleótidos marcados en las roturas existentes en el ADN. Se empleó el protocolo del kit comercial «Insitu Cell Death Detection Kit, Fluorescein» (Roche). Brevemente, en un tubo Eppendorf se depositaron $300 \mu \mathrm{L}$ de solución espermática y $1 \mathrm{~mL}$ de buffer fosfato salino (PBS). La mezcla se centrifugó a 400 g por 10 min y se retiró el sobrenadante. El pellet fue resuspendido en $1 \mathrm{~mL}$ de formaldehído $37 \%$ e incubado por 1 hora a temperatura ambiente. Luego se centrifugó a 400 g por 10 min y el pellet se resuspendió en $30 \mu \mathrm{L}$ de sobrenadante. Se depositó $10-$ $20 \mu \mathrm{L}$ de la solución en un portaobjeto el cual se secó en platina temperada a $37^{\circ} \mathrm{C}$. Una vez seco el frotis, fue hidratado con PBS tres veces y permeabilizados con TRITON $0.1 \%$ en citrato de sodio $0,1 \%$ a $4^{\circ} \mathrm{C}$ e incubados en presencia de los nucleótidos marcados y de la enzima terminal deoxinucleotidil transferasa. Posteriormente, se

realizó una contra-tinción con yoduro de propidio $1 \mu \mathrm{L} / \mathrm{ml}$ en PBS. Las placas fueron evaluadas en microscopio de epifluorescencia (Zeiss, Axiolab). Se evaluaron al menos 200 células.

Determinación de ión superóxido $\left(\mathrm{O}_{2^{-}}\right)$. Para medir $\mathrm{O}_{2}$-- $^{-}$ se utilizo la técnica propuesta por De Iuliis et al. (2006). Se centrifugó una solución espermática conteniendo $2 \times 10^{6}$ espermatozoides $/ \mathrm{mL}$, se extrajo el sobrenadante, y el pellet se resuspendió en $200 \mu \mathrm{L}$ de dihydroethidium (DHE) $2 \mu \mathrm{M}$ y $200 \mu \mathrm{L}$ de SYTOX green $0.05 \mu \mathrm{M}$. Para observar la presencia de $\mathrm{O}_{2}$.- intracelular, se evaluaron 10.000 eventos en un citómetro de Flujo FACSCalibur, Becton Dikinson.

Análisis estadístico. Los resultados fueron analizados mediante software estadístico XLStat-Pro 7.5. A los datos obtenidos se aplico la Prueba no paramétrica de Wilcoxon para la evaluación de muestras pareadas. En todos los casos un valor de $\mathrm{p}<0,05$ fue considerado estadísticamente significativo.

\section{RESULTADOS}

Características del líquido seminal. La edad de los donantes fue entre 24 y 43 años. A las muestras se les realizó un espermiograma antes de someterlas a swim-up, siendo seleccionadas solo aquellas que presentaron espermiogramas normales. Las características del semen nativo y datos promedio de éste \pm la desviación estándar se observan en la Tabla I.

$\square$ Antes de vitrificación

- Después de vitrificación

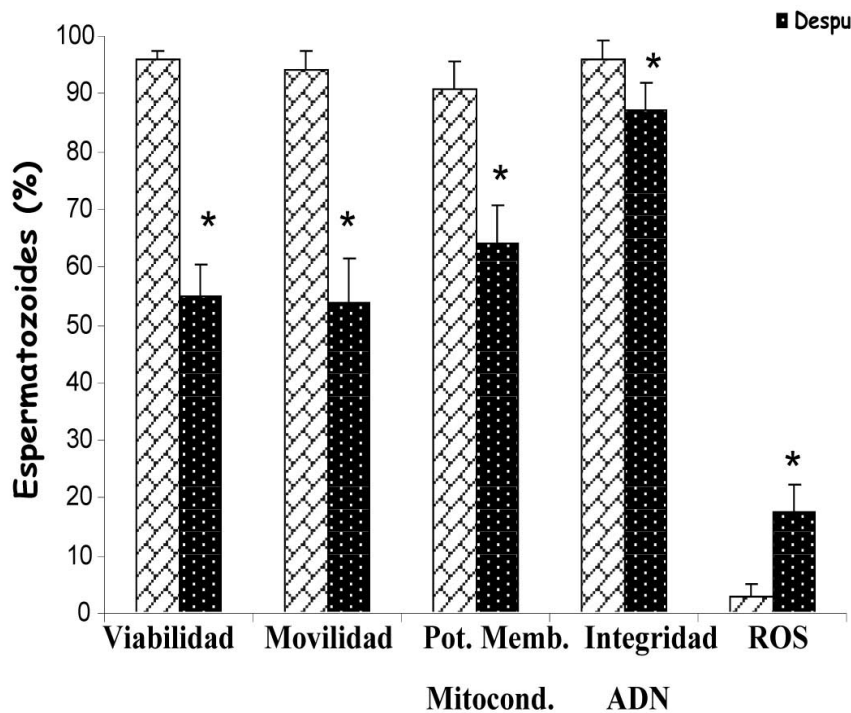

Fig. 1. Indicadores de funcionalidad en espermatozoides seleccionados antes y después de ser vitrificados. Se observan graficados los promedios \pm desviación estándar. (*) Significancia $(\mathrm{p}<0.05)$.
Viabilidad y movilidad. Después de seleccionar los espermatozoides por swim-up, se obtuvo viabilidad de $95,8 \% \pm 1,6 \%$, la cual disminuyó luego de ser sometida a vitrificación la muestra a 55,6\% $\pm 5,6 \%$ de espermatozoides vivos $(\mathrm{p}<0,05)$. La movilidad progresiva fue de $94,3 \% \pm 3,6 \%$ en espermatozoides seleccionados, luego de la vitrificación el porcentaje de células con movimiento progresivo fue de $54,4 \% \pm 7,6 \%$ $(\mathrm{p}<0,05)$ (Fig. 1).

Potencial de membrana mitocondrial. El $91 \% \pm 4,5 \%$ de los espermatozoides post selección espermática presentó conservación del

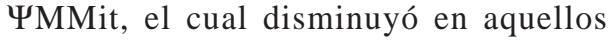
espermatozoides sometidos a vitrificación $(64 \% \pm 6,6 \%)(\mathrm{p}<0,05)$. (Fig. 1). 
Tabla I. Características del espemiograma de los donantes.

\begin{tabular}{lc}
\hline Característica & Evaluación \\
\hline Volumen (ml) & $3,2 \pm 1,3$ \\
Licuefacción & Normal \\
Viabilidad & $80,9 \pm 20,3$ \\
Movilidad progresiva & $50,4 \pm 10,8$ \\
Recuento (Mill/ml) & $125,3 \pm 57,3$ \\
Células. Redondas (Mill/l) & $2,5 \pm 2,5$ \\
Viscosidad & Normal-Aumentada \\
Aspecto & Homogéneo \\
Color & Amarillo grisáceo \\
pH & $8,4 \pm 0,4$ \\
\hline
\end{tabular}

Los valores numéricos se expresan como porcentajes promedios \pm desviación estándar.

Integridad de ADN. Los resultados muestran que el 96\% $\pm 3,4 \%$ de los espermatozoides sin vitrificar presentaron el ADN íntegro, porcentaje que exhibió una leve disminución en aquellas células sometidas a vitrificación $(87 \% \pm 5,0 \%)$ no obstante esta disminución demostró ser estadísticamente significativa $(\mathrm{p}<0,05)($ Fig. 1).

Reacción de Acrosoma. Un 2,6\% $\pm 2,1 \%$ de espermatozoides vivos presentó una espontánea reacción de acrosoma antes de la vitrificación, cifra que aumenta levemente después de ser vitrificados a un $3,8 \%$, aunque este incremento fue estadísticamente significativo $(\mathrm{p}<0,05)$. La inducción con ionóforo de calcio provocó que el $26,7 \% \pm 9,2 \%$ de los espermatozoides no vitrificados experimentara reacción de acrosoma, mientras que sólo el $13,1 \% \pm 4,1 \%$ de éstos reaccionaron después de la vitrificación ( $\mathrm{p}<0,05)$ (Fig. 2).

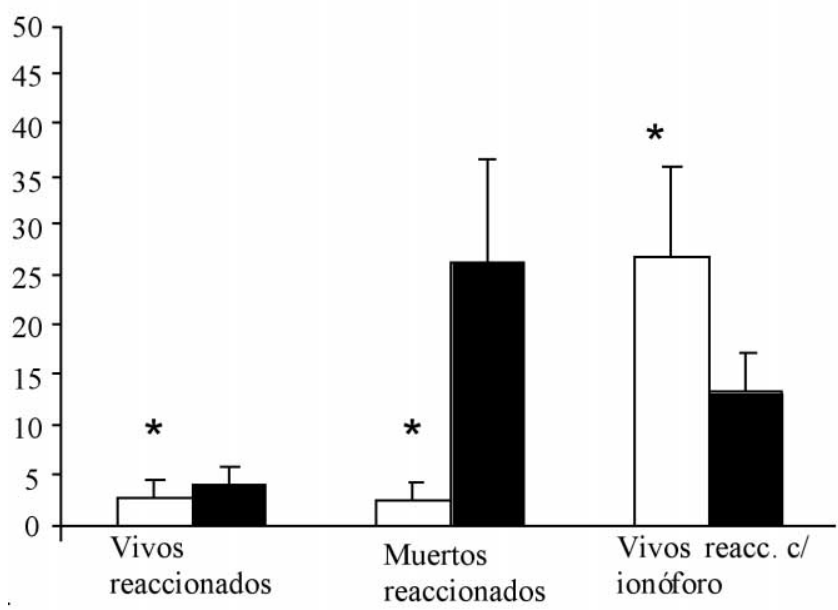

Fig. 2. Porcentajes de espermatozoides humanos que experimentaron reacción de acrosoma espontanea e inducidos con ionóforo de calcio antes y después de ser sometidos a vitrificación. Se observan graficados los promedios \pm desviación estándar. (*) Significancia $(\mathrm{p}<0.05)$.
Superóxido intracelular. Posterior a su descongelación un $17,6 \% \pm 4,9 \%$ de los espermatozoides vitrificados presentaron un incremento de células con tinción positiva para $\mathrm{O}_{2 \cdot-}$, evidenciando una mayor producción de especies reactivas de oxigeno en comparación al 3,0\% $\pm 2,3 \%$ de aquellos que no fueron vitrificados $(\mathrm{p}<0,05)$ (Fig. 1). Los histogramas para la tinción de $\mathrm{O}_{2}$.- intracelular en muestras sin vitrificar y vitrificadas, se observan en la Fig. 3.

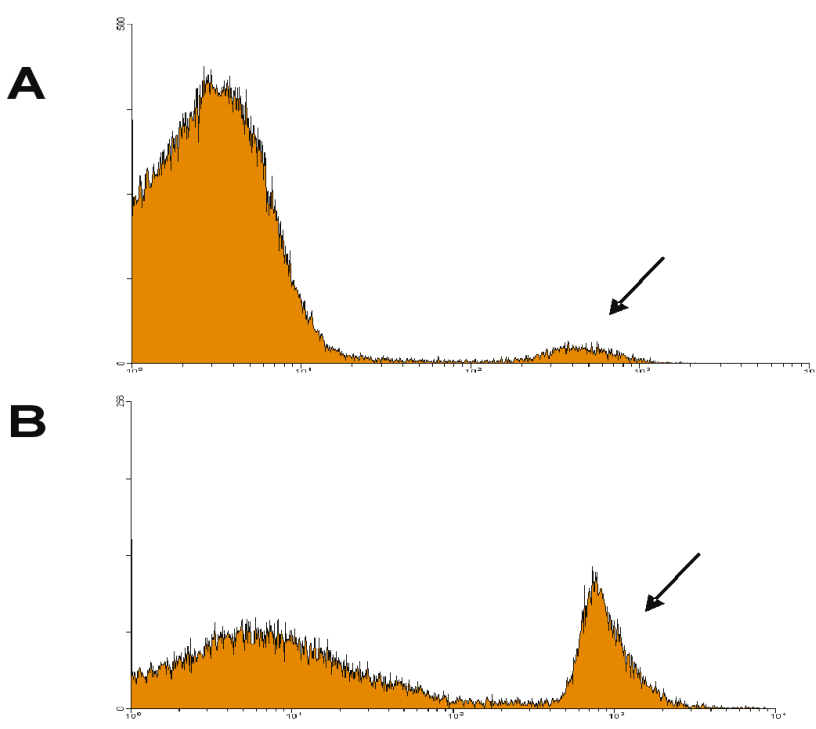

Fig. 3. Histograma A: una pequeña población de espermatozoides

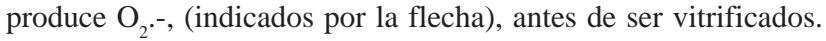
Histograma B: aumento de los espermatozoides generadores de éste radical después de la vitrificación

\section{DISCUSIÓN}

La vitrificación es una forma de congelación ultra rápida, posible de ser utilizada en la preservación de gametos. Este tipo de criopreservación, consiste en elevar la viscosidad de los líquidos intra y extracelulares para obstaculizar la difusión, deteniendo finalmente todos los procesos celulares (Isachenko et al., 2003).

Una de las ventajas de la vitrificación, es evitar la formación de cristales de hielo intracitoplasmáticos, los cuales inducen daño y pérdida de la función celular, éstos son el principal obstáculo que presenta la criopreservación tradicional, razón por lo cual, la vitrificación se ha planteado como una solución a la criopreservación lenta.

Entre las características que hacen más atractiva la vitrificación frente a la criopreservación tradicional, se encuentran la rapidez con la que puede ser realizada, la facilidad de su procedimiento y el no necesitar de instrumental 
sofisticado para su ejecución, lo cual disminuye su costo, elementos importantes al momento de determinar los costos para la conservación celular.

En el presente estudio se utilizaron una serie de pruebas de funcionalidad espermática para observar el efecto de la vitrificación en espermatozoides de pacientes normozoospérmicos, aquí la viabilidad de los espermatozoides sometidos a swim-up fue superior a la observada en el líquido seminal, lo que advierte sobre la conveniencia de seleccionar los espermatozoides antes de ser sometidos a criopreservación. Minimizando asi, el riesgo de contaminación por microorganismos presentes en el plasma seminal (Mazzilli et al., 2006)

Los porcentajes de viabilidad obtenidos en este estudio están en concordancia al ser comparados con otros trabajos donde se ha aplicado un protocolo similar de vitrificación (Isachenko et al., 2008). Sin embargo, cuando se aplican protocolos de criopreservación lenta, principalmente utilizando vapores de nitrógeno líquido, los porcentajes de viabilidad obtenidos son mucho menor a los logrados en este trabajo (Keel et al., 1987; Rossato et al., 2000; Esteves et al., 1998; Estevez et al., 2000; O'Connell et al., 2002; Schulz et al., 2007).

Al respecto, la mortalidad espermática producida durante la criopreservación lenta podría estar originado por el efecto de los crioprotectores, estrés celular y estrés osmótico (Stornelli et al.). Todos estos elementos afectarían severamente el volumen celular, al exponer los espermatozoides a ciclos de congelamiento y descongelamiento. Los crioprotectores permeables en altas concentraciones también se utilizaron para vitrificar espermatozoides. El problema de estos solventes, radica en que la mayoría tienen carácter tóxico, produciendo daño osmótico a las célula, deterioro que se agudiza, considerando las características de tamaño y escaso citoplasma con el que cuentan los espermatozoides (Isachenko et al., 2004a, b). El protocolo de vitrificación aquí utilizado, no considera crioprotectores permeables, sino uno impermeable en bajas concentraciones (sucrosa), el que resulta más inocuo y disminuye el daño celular al momento de la criopreservación.

Además de la viabilidad, la motilidad es otro de los indicadores que se ve severamente afectado cuando se aplican algunos protocolos de criopreservación, de ésta depende la capacidad del espermatozoide para una fecundación exitosa. En el presente trabajo se observó gran cantidad de espermatozoides vivos con movimiento progresivo después de ser vitrificados. Valores que experimentan un notable descenso cuando se han utilizado otros tipos de criopreservación (Estevez et al., 2000; Schulz et al.).
El potencial de membrana mitocondrial disminuyó en un bajo porcentaje de espermatozoides vitrificados, hecho que resulta interesante, puesto que otro de los problemas que presenta la criopreservación lenta es la severa disminución de este indicador en los espermatozoides descongelados (O'Connel et al.; Schulz et al.). Por la trascendencia que adquiere la función mitocondrial en el espermatozoide, la evaluación de ésta se ha asociado a varias funciones espermáticas, como motilidad o estado de la cadena respiratoria, la que involucraría indirectamente la producción de ROS e incluso el metabolismo general de la célula. Al respecto se ha encontrado que al correlacionar potencial mitocondrial con movilidad o fertilidad se encuentra en ambos casos una elevada correlación (Marchetti et al., 2004).

Una forma de detectar la capacidad de fecundación del espermatozoide, es revelando el estado en que se encuentra el acrosoma, el cual idealmente deberá encontrarse intacta. Después de la vitrificación hubo un leve aumento del porcentaje de espermatozoides vivos que presentaron reacción de acrosoma espontánea. Este proceso que es altamente sensible a los cambios de temperatura (Sanchez \& Schill, 1991; Ortloff et al., 2006), en el proceso de criopreservación lenta se ha descrito un alto porcentaje de criocapacitación y reacción acrosomal espontánea de los espermatozoides (McLaughlin et al., 1992; Esteves et al., 1998; Esteves et al., 2000; Esteves et al., 2007; Schulz et al.).

La reacción acrosomal es un proceso especializado que implica la fusión de la membrana citoplasmática con la membrana acrosomal externa en la zona apical de la cabeza del espermatozoide, este ocurre entre membranas intactas y con función conservada. Al comparar los promedios de espermatozoides reaccionados con y sin ionóforo, se observa que el porcentaje de reaccionados es menor después de la vitrificación, lo cual también podría relacionarse al deterioro de la membrana plasmática por efecto de la vitrificación, esto afectaría la depolarización de la membrana, teniendo como consecuencia el mal funcionamiento de canales regulados por voltaje, entre los que se encuentran los canales de calcio, alterando así el normal flujo del ión hacia las células, elemento esencial para la reacción de acrosoma (James et al., 1999; Rossato et al.). Este proceso puede estar asociado al incremento de ROS generados durante la descongelación (Agarwal et al., 2008).

Las ROS comprenden una serie de compuestos químicos altamente reactivos, que tienen un electrón desapareado lo que los hace muy inestables. Entre ellos se destacan el anión superóxido $\left(\mathrm{O}_{2} \cdot-\right)$, radical peróxido (ROO), anión hidroxilo $\left(\mathrm{OH}^{-}\right)$y una especie no radical, el peróxido de hidrógeno $\left(\mathrm{H}_{2} \mathrm{O}_{2}\right)$ entre otros. El incremento de ROS ha sido asociado a disminución de la función espermática, especialmente pérdida de 
la fluidez de membrana, que disminuye la capacidad de fusión al ovocito, como asimismo el incremento de la fragmentación del ADN que conlleva a fallas en el desarrollo embrionario (Agarwal, 2004; Agarwal \& Said, 2005).

Los resultados de este estudio no muestran un aumento considerable de $\mathrm{O}_{2}$.- en los espermatozoides posterior al swin-up, aún al mantenerlos un par de horas a temperatura ambiente antes de someterlos a congelación. Después de ser vitrificados solo el 17.6\% de ellos sufrió aumento de éste radical, lo cual podría estar relacionado a la buena calidad y funcionamiento de los mecanismos antioxidante que portan los espermatozoides de los individuos sanos, donde la carga enzimática al parecer no se vería afectada después de haber sido sometida a bajas temperaturas. Es probable, que la albúmina en el medio de cultivo, también haya ejercido un efecto protector (Twigg et al., 1998; Agarwal et al., 2004).

En otro aspecto, el porcentaje de células que sufrieron fragmentación del ADN fue solo el $9 \%$ de los espermatozoides postvitrificados, lo que estaría indicando que este tipo de criopreservación al parecer no dañaría severamente el material genético, hecho favorable, considerando que a este componente se le han atribuido disminución de la capacidad de fecundación y en algunos casos efectos mutagénicos (Isachenko et al., 2004). Este porcentaje de fragmentación del ADN es similar a los que produce la congelación lenta (Isachenko et al., 2004a, b), y en general son bajos respecto al valor de $20 \%$ que se ha establecido como indicador de un daño patológico al ADN en el hombre (Agarwal \& Said, 2005).

La vitrificación como técnica de criopreservación de espermatozoides presenta varias ventajas con respecto a la congelación lenta o tradicional, entre estas se encuentran aquellas relacionadas con indicadores de funcionalidad espermática, pues como se ha constatado en el presente trabajo, indicadores como viabilidad, movilidad, integridad del material genético, potencial mitocondrial e integridad del acrosoma presentaron resultados mucho más favorables a los descritos en la criopreservación tradicional. A esto se debe agregar otros factores que lo hacen más conveniente ya que, el sumergir a las células directamente en nitrógeno líquido es mucho más rápido, de menor costo y un procedimiento relativamente fácil de realizar. No obstante, es necesario seguir perfeccionando este tipo protocolo para disminuir el daño espermático, posiblemente con el uso de antioxidantes para modular el incremento de ROS que se generan en el proceso de congelación, y así lograr una célula con indicadores similares a aquellos presentados por espermatozoides sin vitrificar.

BERRIOS, S. O. \& SÁNCHEZ, G. R. Ultra rapid freezing in human spermatozoa: Effect on sperm function and reactive oxygen species production. Int. J. Morphol., 29(3):899-906, 2011.

SUMMARY: The number of patients who wish to maintain their fertility is ever increasing. This group of patients includes cancer patients, those with fertility problems or viral infectious diseases acquired through sexual contact and others submitting to voluntary surgical sterilization; all of the above requiring freezing methods to adequately preserve sperm function. In the field of cryobiology the use of ultra-rapid freezing techniques has successfully preserved oocytes, embryos and ovarian tissue. This method has recently been incorporated in preserving male gametes. This study evaluates the effect of ultra-rapid freezing (vitrification) on sperm function of 10 normozoospermic donors. The sperm were selected by swim-up technique and the solution divided into two fractions. One fraction is vitrified by dipping directly into liquid nitrogen and the second fraction is used as control. In both fractions, viability, motility, mitochondrial membrane potential ( $\Psi$ MMit) DNA integrity, spontaneous and induced acrosome reaction and intracellular superoxide $\left(\mathrm{O}_{2} .^{-}\right)$were determined. It was noted that vitrification preserves cell function in a great number of spermatozoon, and is also simple, rapid and cost effective as this method does not require freezing equipment. There is however, significant activation of the production of reactive oxygen species, which leads to premature sperm capacitation, an event necessary to modulate particularly when using these cells in intrauterine insemination techniques. Future studies with addition of antioxidants to freezing media are necessary to further improve this technique.

KEY WORDS: Human spermatozoa; Cryopreservation; Ultra rapid freezing; Sperm function; Reactive oxygen species.

\section{REFERENCIAS BIBLIOGRAFICAS}

Agarwal, A.; Makker, K. \& Sharma, R. Clinical relevance of oxidative stress in male factor infertility: an update. Am. J. Reprod. Immunol., 59(1):2-11, 2008.

Agarwal, A.; Nallella, K. P.; Allamaneni, S. S. \& Said, T. M. Role of antioxidants in treatment of male infertility: an overview of the literature. Reprod. Biomed. Online, 8(6):616-27, 2004.

Agarwal, A. \& Said, T. M. Oxidative stress, DNA damage and apoptosis in male infertility: a clinical approach. $B J U$ Int., 95(4):503-7, 2005. 
De Iuliis, G. N.; Wingate, J. K.; Koppers, A. J.; McLaughlin, E. A. \& Aitken, R. J. Definitive Evidence for the Nonmitochondrial Production of Superoxide Anion by Human Spermatozoa. J. Clin. Endocrinol. Metab., 91(5):1968-75, 2006.

Desrosiers, P.; Légaré, G.; Leclerc, P. \& Sullivan, R. Membranous and structural damage that occurs during cryopreservation of human sperm may be time-related events. http://www.fertstert.org/article/PIIS001502820 6003633/abstract - article-footnote-1\#article-footnote1Fertil. Steril., 85(6):1744-52, 2006.

Estevez, S. C.; Sharma, R. K.; Thomas, A. J. Jr. \& Agarwal, A. Cryopreservation of human spermatozoa with pentoxifylline improves the post-thaw agonist-induced acrosome reaction rate. Hum. Reprod., 13(12):3384-9, 1998.

Estevez, S. C.; Sharma, R. K.; Thomas, A. J. Jr. \& Agarwal, A. Improvement in motion characteristic and acrosome status in cryopreserved human spermatozoa by swimup processing before freezing. Hum. Reprod., 15(10):2173-9, 2000.

Esteves, S. C.; Spaine, D. M. \& Cedenho, A. P. Effects of pentoxifylline treatment before freezing on motility, viability and acrosome status of poor quality human spermatozoa cryopreserved by the liquid nitrogen vapor method. Braz. J. Med. Biol. Res., 40(7):985-92, 2007.

Fahy, G.; MacFarlane, D. R.; Angell, C. A. \& Meryman, H. T. Vitrification as an approach to cryopreservation. Cryobiology, 21(4):407-26, 1984.

Isachenko, E.; Isachenko, V.; Katkov, I. I.; Dessole, S. \& Nawroth, F. Vitrification of mammalian spermatozoa in the absence of cryoprotectants: from past practical difficulties to present success. Reprod. Biomed. Online, 6(2):191-200, 2003.

Isachenko, E.; Isachenko, V.; Katkov, I. I.; Rahimi, G.; Schöndorf, T.; Mallmann, P.; Dessole, S. \& Nawroth, F. DNA integrity and motility of human spermatozoa after standard slow freezing versus cryoprotectant-free vitrification. Hum. Reprod. 19(4):932-9, 2004 a.

Isachenko, V.; Isachenko, E.; Katkov, I. I.; Montag, M.; Dessole, S.; Nawroth, F. \& Van Der Ven, H. Cryoprotectant-free cryopreservation of human spermatozoa by vitrification and freezing in vapor: effect on motility, DNA integrity, and fertilization ability. Biol. Reprod., 71(4):1167-73, $2004 \mathrm{~b}$.
Isachenko, E.; Isachenko, V.; Weiss, J. M.; Kreienberg, R.; Katkov, I. I.; Schulz, M.; Lulat, A. G.; Risopatrón, M. J. \& Sánchez, R. Acrosomal status and mitochondrial activity of human spermatozoa vitrified with sucrose. Reproduction, 136(2):167-73, 2008.

James, P. S.; Wolfe, C. A.; Mackie, A.; Ladha, S.; Prentice, A. \& Jones, R. Lipids dynamics in the plasma membrane of fresh and cryopreserved human spermatozoa. Hum. Reprod., 14(7):1827-32, 1999.

Keell, B. A.; Webster, B. W. \& Roberts, D. K. Effects of cryopreservation on the motility characteristics of human spermatozoa. J. Reprod. Fertil., 81(1):213-20, 1987.

Mazzilli, F.; Delfino, M.; Imbrogno, N.; Elia, J. \& Dondero, F. Survival of micro-organisms in cryostorage of human sperm. Cell Tissue Bank., 7(2):75-9, 2006.

McLaughlin, E.; Ford, W. C. \& Hull, M. G. Motility characteristics and membrane integrity of cryopreserved human spermatozoa. J. Reprod. Fertil., 95(2):527-34, 1992.

Marchetti, C.; Jouy, N.; Leroy-Martin, B.; Defossez, A.; Formstecher, P. \& Marchetti, P. Comparison of four fluorochromes for the detection of the inner mitochondrial membrane potential in human spermatozoa and their correlation with sperm motility. Hum. Reprod., 19(10):2267-76, 2004.

Ngmwuttiwong, T. \& Kunathikom, S. Evaluation of cryoinjury of sperm chromatin according to liquid nitrogen vapour method (I). J. Med. Assoc. Thai., 90(2):224-8, 2007.

O’Connell, M.; McClure, N. \& Lewis, S. E. The effects of cryopreservation on sperm morphology, motility and mitocondrial function. Hum. Reprod., 17(3):704-9, 2002.

Ortloff, C.; Deppe, M.; Schill, W. B. \& Sánchez, R. A new technique to evaluate the ability of cryoprotectors to prevent premature acrosome reaction in human spermatozoa. Andrología, 38(6):230-2, 2006.

Quinn, P.; Kerin, J. F. \& Warnes, G. M. Improved pregnancy rate in human in vitro fertilization with the use of a medium based on the composition of human tubal fluid. Fertil. Steril., 44(4):493-8, 1985.

Rossato, M.; Zorzi, M.; Ferlin, A.; Garolla, A. \& Foresta, C. Effects of cryopreservation on progesterone - induced ion fluxes and acrosome reaction in human spermatozoa. Hum. Reprod., 15(8):1739-43, 2000. 
BERRIOS, S. O. \& SÁNCHEZ, G. R. Congelación ultra rápida de espermatozoides humanos: Efecto sobre la función espermática y producción de especies reactiva de oxígeno. Int. J. Morphol., 29(3):899-906, 2011.

Sanchez, R. \& Schill, W. B. Induction of the acrosome reaction in sperm by exposure to low temperature increases their rate of fusion with zona-free hamster oocytes. Int. J. Androl., 14(6):423-30, 1991.

Schulz, M.; Sánchez, R. \& Risopatrón, J. Implementación de la técnica de vitrificación aséptica de espermatozoides humanos. Rev. Argent. Androl., 16(2):61, 2007.

Stornelli, M. C.; Tittarelli, C. M.; Savignone C. A. \& Stornelli, M. A. Efecto de los procesos de criopreservación sobre la fertilidad seminal. Analecta Vet., 25(2):28-35, 2005.

Twigg, J.; Fulton, N.; Gomez, E.; Irvine, D. S. \& Aitken, R. $\mathrm{J}$. Analysis of the impact of intracellular reactive oxygen species generation on the structural and functional integrity of human spermatozoa: lipid peroxidation, DNA fragmentation and effectiveness of antioxidant. Hum. Reprod., 13(6):1429-36, 1998.

World Health Organization (WHO), Department of Reproductive Health and Research. WHO laboratory manual for the examination and processing of human semen. 5a. Ed. Geneva, World Health Organization, 2010.

Yildiz, C.; Ottaviani, P.; Law, N.; Ayearst, R.; Liu, L. \& McKerlie, C. Effects of cryopreservation on sperm quality, nuclear DNA integrity, in vitro fertilization, and in vitro embryo development in the mouse. Reproduction, 133(3):585-95, 2007.
Dirección para correspondencia:

Dr. Raúl Sánchez Gutiérrez

Departamento de Ciencias Preclínicas

Facultad de Medicina

Universidad de La Frontera

Manuel Montt 112, Temuco

CHILE

Email: rsanchez@ufro.cl

Recibido : 17-05-2011

Aceptado: 29-06-2011 